\title{
Peter Longerich, Antisemitismus: Eine deutsche Geschichte. Von der Aufklärung bis heute.
}

\section{Etienne Schinkel}

\section{OpenEdition}

\section{Journals}

Electronic version

URL: https://journals.openedition.org/ifha/11575

DOI: 10.4000/ifha. 11575

ISSN: 2198-8943

\section{Publisher}

IFRA - Institut franco-allemand (sciences historiques et sociales)

\section{Electronic reference}

Etienne Schinkel, "Peter Longerich, Antisemitismus: Eine deutsche Geschichte. Von der Aufklärung bis heute.", Revue de l'IFHA [Online], Date of review, Online since 20 December 2021, connection on 22 December 2021. URL: http://journals.openedition.org/ifha/11575; DOI: https://doi.org/10.4000/ifha. 11575

This text was automatically generated on 22 December 2021.

(C)IFHA 


\title{
Peter Longerich, Antisemitismus: Eine deutsche Geschichte. Von der Aufklärung bis heute.
}

\author{
Etienne Schinkel
}

Le 9 octobre 2019, un terroriste lourdement armé a tenté d'entrer par la force dans la synagogue de Halle, qui comptait 80 personnes. L'attentat planifié a échoué, mais il a de manière dramatique fait prendre conscience de la menace réelle qui pèse sur les Juives et Juifs en Allemagne. Des drapeaux israéliens en feu, des monuments et des cimetières violés, des brutalités physiques et des agressions verbales contre des personnes de confession juive - la liste des violences antijuives est longue, les crimes antisémites sont en augmentation.

Il n'est donc pas étonnant que les recherches sur l'histoire de l'antisémitisme et sa présence actuelle aient conjoncture. Depuis 2015, le «Manuel de l'antisémitisme » édité par

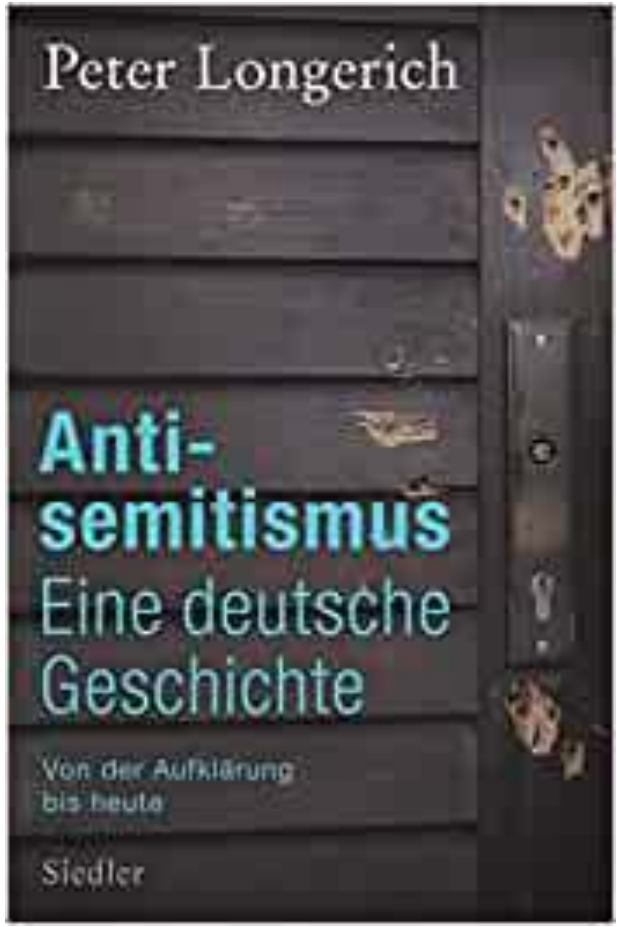
Wolfgang Benz est complètement disponible, un ouvrage de référence en huit volumes qui rassemble toutes les connaissances scientifiquement prouvées sur l'antisémitisme de manière interdisciplinaire et sans limite de temps et d'espace. ${ }^{1}$ Récemment, sous l'effet de l'actualité, de nombreux scientifiques de renom ont publié des études qui tentent d'expliquer comment les stéréotypes antisémites se sont 
répandus depuis l'Antiquité, ont conduit à la persécution et à l'extermination et sont restés virulents après la Shoah. ${ }^{2}$

En ce qui concerne la persistance de l'antisémitisme, Peter Longerich, un des chercheurs le plus reconnu en vue de l'histoire du national-socialisme, a également écrit un livre dans lequel il décrit les différentes formes d'hostilité envers les Juifs en Allemagne du siècle des Lumières jusqu'à aujourd'hui. Pour Longerich, dont les livres sur la "Politique d'extermination» (1998) ainsi que l'écho qu'elle a eu dans la population allemande, « Nous ne savions pas » (2006), sont des ouvrages de référence et dont les biographies monumentales de Heinrich Himmler (2008), de Joseph Goebbels (2010) et d'Adolf Hitler (2015) ont retenu l'attention internationale, se pose les questions suivantes: Pourquoi les Juifs sont-ils toujours victimes de discrimination et de violence ? Pourquoi n'ont-ils pas été et ne sont-ils pas acceptés comme égaux ? Sa thèse : Le sentiment d'identité allemande est étroitement lié au rejet du juif.

Dans son ouvrage approfondi, Longerich expose une étonnante abondance d'exemples datant de près de deux siècles et demi, qui témoignent en paroles et en actes de l'antisémitisme "des Allemands »: qu'il s'agisse - à première vue - d'une insistance inoffensive sur les différences culturelles ou religieuses, d'un antisémitisme meurtrier dans les attentats et les pogroms ou, enfin, dans l'Holocauste. L'antisémitisme, selon Longerich, est en quelque sorte le côté négatif d'une formation identitaire allemande ratée.

L'historien explique comment la haine antisémite très ancienne prend des dimensions de plus en plus grandes, précisément à l'époque des Lumières, comment les Nationalistes romantiques combattent l'émancipation de la minorité juive, comment ils stigmatisent les Juifs comme étant des " non-Allemands", comment des fantasmes violents se développent déjà il y a 200 ans, où même l'extermination physique des Juifs est envisagée dans le débat sur l'égalité juridique. On lit que même les grands esprits comme Johann Gottfried Herder ou Johann Gottlieb Fichte se battent contre des Juifs supposés parasitaires. En raison de leur recherche récurrente d'identité nationale (par exemple ascendance, langue ou culture commune), «les Allemands », dit l'auteur, ne peuvent pas supporter les Juifs comme des citoyens égaux en droits. L'historien démontre de manière impressionnante que l'on cherche toujours des raisons complètement absurdes pour faire apparaître les Juifs comme les autres que l'on veut exclure de sa propre communauté ou de la nation (en train de naître) qu'on cherche avec insistance : accusation de pratiques économiques juives frauduleuses-raffinées, de « décomposition » culturelle, de manque de fiabilité nationale, etc. En outre, Longerich explique de manière différenciée comment " les Allemands » se construisent plus tard, avec des mythes nationaux, une histoire de l'allemand dans laquelle les Juifs ne peuvent pas s'insérer. Dans l'Empire allemand de 1871 à 1918, les antisémites dénoncent les Juifs comme étant un ennemi de l'État. Dans la République de Weimar, l'antisémitisme devient critique de l'establishment, germe de la politique d'extermination nazie.

Selon une thèse répandue, « les Juifs » sont des boucs émissaires en temps de crise pour détourner l'attention des véritables problèmes sociaux, économiques ou politiques. L'antisémitisme prend donc de l'importance, par exemple, lors des troubles révolutionnaires qui suivent la Première Guerre mondiale ou lors de la crise économique à la fin des années 1920. Longerich estime que cette explication est insuffisante parce qu'elle n'explique pas suffisamment pourquoi les Juifs ont toujours 
été les victimes de telles crises. De manière plausible, l'auteur démontre par de nombreux exemples qu'il ne s'agit pas seulement d'un phénomène de crise, mais du côté négatif d'une recherche d'identité nationale : «le Juif » comme la déformation de l'Allemand patriotique. Ce n'est pas avec l'arrivée au pouvoir des nazis que l'antisémitisme a trouvé un terrain fertile. Les bases psychologiques de la politique antisémite radicale à partir de 1933 avaient déjà été préparées le terrain dans les années stable de la République de Weimar: dans le camp national-allemand, dans les associations armées et économiques, dans une grande partie de la communauté étudiante, dans la justice et dans l'Église protestante. L'antisémitisme n'est donc pas non plus une question de marginaux. Au contraire: Vers 1900 par exemple, la citoyenneté cultivée était la plus grande supportrice de l'hostilité envers les Juifs.

Dans l'ensemble, l'étude de Longerich offre un aperçu pointu et instructif de l'histoire allemande de l'antisémitisme. L'historien réussit à donner en détail des idées principales tirées des œuvres-clés d'antisémitisme et des écrits largement inconnus. Il en résulte une vue d'ensemble selon laquelle l'antisémitisme allemand n'est pas un phénomène temporaire, mais un préjugé profondément enraciné dans notre histoire et notre culture.

\section{NOTES}

1. Cf. Wolfgang Benz (éd.): Handbuch des Antisemitismus. Judenfeindschaft in Geschichte und Gegenwart. 8 Bde. Berlin 2008-2015.

2. Cf. par exemple Achim Bühl: Antisemitismus. Bd. 1: Geschichte und Strukturen von der Antike bis 1848. Bd. 2: Geschichte und Strukturen von 1948 bis heute. Wiesbaden 2019/2020; Micha Brumlik: Antisemitismus. 100 Seiten. Ditzingen 2020; Peter Schäfer: Kurze Geschichte des Antisemitismus. München 2020.

INDEX

Chronological index: Ouvrage transpériodique

Subjects: histoire de la culture, histoire des États et des pouvoirs, Histoire des idées

\section{AUTHOR}

ETIENNE SCHINKEL

Universität Göttingen 